\title{
The Involvement of Stakeholders in Promoting the Wellness of Juvenile Offenders in Selected South African Correctional Schools
}

\author{
Forget Makhurane \\ PhD candidate, Department of Educational Psychology, \\ University of South Africa, Pretoria, South Africa
}

\begin{abstract}
The main focus of the study was to explore the involvement of stakeholders in promoting the wellness of juvenile offenders in South African correctional schools. Two teachers and three juveniles were purposefully selected to complete open ended questionnaires from two juvenile centres in the Western Cape province of South Africa. The major aim of the study was to identify how different stakeholders can facilitate the attainment of wellness among juvenile offenders. The ubuntu and wellness theories were used as lenses to carry out the study. Research ethic procedures were followed. In order to get livid experience of participants, qualitative method was used to collect and analyse data. Findings revealed that stakeholder involvement varied with some being more involved while others were lacking. This compromised effective rehabilitation. It was recommended that the involvement of stakeholders should be intensified in order to have a greater impact on the rehabilitation of juvenile offenders.
\end{abstract}

Keywords: stakeholders, wellness, juveniles, rehabilitation, recidivism, offenders

\section{Introduction}

Rehabilitation of juvenile offenders should be effective in order to reduce recidivism. Recidivism is a societal problem since the tax payers' money is used for the up keep of inmates who return to crime after undergoing rehabilitation. In the United States of America, studies showed that juveniles who became adult offenders cost the state between 1.5 billion dollars to 1.8 billion dollars each (Macomber, Skiba, Blackmon, Hart, Mambrino, Richie \& Grigorenko 2010). South Africa has also experienced high recidivism rate which was estimated to be about 80\% in 2012 (ReAducate 2012). Owing to the negative impact of ineffective rehabilitation to society, the Department of Correctional Services states that the rehabilitation of offenders should not be viewed as the responsibility of one department but as a societal responsibility (Department of Correctional Services 2005). According to the wellness model, there 
are different wellness dimensions that an individual need to accomplish in order to attain total wellness (Hetler 1976). These dimensions are social, intellectual, emotional, spiritual, career and physical (Hetler 1976). In order to promote different wellness dimensions among juvenile offenders, it is necessary therefore to involve various stakeholders who play different roles in the lives of juvenile offenders. Moreover, crime and recidivism are societal problems that need members of the community to stand together (Ngabonziza \& Singh 2012). This is in line with the philosophy of $u$ buntu which states that every member of the community has a role to play in ensuring that a healthy society is maintained as he considers himself part of the whole (Metz \& Gaie 2010).

China has implemented an effective programme that ensures different stakeholders play a vital role in juvenile rehabilitation (Chen 2000). According to the same author, some of the stakeholders who are effectively involved include parents, public leaders, Government officials, unions, schools, prospective employers, correctional staff and many more. In South Africa, stakeholder involvement has been identified as key to effective offender rehabilitation (Department of Correctional Services 2005). The implementation needs to be intensified to attain a higher success rate in juvenile rehabilitation.

The family is considered as the basic unit of society that can play a significant role in the rehabilitation of juveniles and in the aftercare programme (Department of Correctional Services 2005). Research has shown that detaining juveniles closer to their families improves their mood and also reduces recidivism (Walker \& Bishop 2016). In South Africa family involvement in the rehabilitation of juveniles is considered to be crucial also (Department of Correctional Services 2005). However, some research findings have revealed that in reality some juveniles are detained far away from their families and stay for longer periods without getting in contact with their families (Muntingh \& Ballard 2012). In the state of Missouri in the United States of America, juveniles are detained closer to their families as much as possible and their families play an active role in their rehabilitation and this has resulted in successful rehabilitation (Dubin 2012).

After care programmes play a vital role in the rehabilitation of juvenile offenders and therefore such programmes need to be more effective and individualised (James, Asscher, Jan, Stams \& Van Der Laan 2016). These programmes are implemented outside correctional centres and therefore relevant stakeholders need to be very active and effective to ensure a high success rate. Offenders such as those on drug and substance abuse rehabilitation need to continue receiving treatment after release to avoid a relapse and re offending (Shrum 2004). In South Africa, programmes such as Khulisa play a vital role in ensuring that offenders are given the necessary support (NICRO 2014).

Research has shown that most juveniles commit crime because of poverty in South Africa due to the increasing gap between the poor and the rich (Langa 2006). Juveniles 
therefore need to be rehabilitated and equipped with skills that can help them live a fulfilling life and stay away from crime. Ubuntu philosophy advocates for fair distribution of resources in society for the benefit of all (Broodryk 2006). The Government should therefore ensure that resources are evenly distributed by the state to ensure equity. During rehabilitation, career guidance and counseling should be given to juveniles so that they can make better and informed choices on careers to sustain their livelihood without resorting to crime. They should also be equipped with relevant skills that can help them fend for themselves and their families after release. In Ireland, an effective after care project called HOPE was used as a way of preparing juveniles for life after release by assisting them with housing, training programmes and other related issues (Lorenz 2002). Different stakeholders were assigned to look at the different needs of juveniles. By involving stakeholders to deal with specific needs of juveniles, released offenders were in a better position to adjust as their basic needs were met. If juveniles are provided with basic needs, it is likely that juvenile crime and recidivism may be reduced. In China also, correctional staff liaise with workplaces, schools and neighbourhood by paying them visits to discuss the return of juvenile offenders and give reports on their transformations (Chen 2000).

If communities are made aware of these transformations, they are likely to accept and embrace juveniles on their return. The philosophy of ubuntu strives for equal treatment for all and therefore by embracing returning juveniles, this philosophy will also be embraced.

\section{Problem Statement}

In 2012, South Africa had one of the highest incarceration rate in the world which was double that of any European country (Wamsley 2012). This state of affairs is a cause for concern which needs special attention. The other concern raised was that the recidivism rate was reported to be very high in the country (McAree 2011; NICRO 2014). This high incarceration and recidivism rates may signal ineffective rehabilitation programmes. According to research done in South Africa, most offenders leave correctional centres the same way they went in due to ineffective offender rehabilitation (NICRO 2009). These revelations therefore create a gap that needs to be filled in with regard to what can be done to ensure effective offender rehabilitation in South Africa. Through the lens of $u b u n t u$, collaborative and collective ways are required to ensure striving for a common cause for a better life for all in society. With regard to achieving effective rehabilitation and reducing recidivism, it is important for different stakeholders to work hand in hand to achieve a successful rehabilitation programme.

\section{Theoretical Framework}

In this study, ubuntu philosophy as well as the wellness theory were used as lenses to carry out the study. Ubuntu encourages people to work together in different settings for the good of all (Maphalala 2017). It also looks at the significance of the 
interconnectedness of human society with the emphasis that a person is incomplete without community (Tutu 1999). In view of these philosophies, the study sought to explore how different stakeholders can work together to ensure the effective rehabilitation of juvenile offenders. According to ubuntu, success needs people to put hands together (Mangena 2016). From this perspective, the implication is that stakeholders should come together in order to achieve a successful rehabilitation programme. The wellness theory fits in this study since it stipulates that for wellness to be achieved, different dimensions of wellness have to be attained first (Hetler 1976). These dimensions can be attained through the involvement of different stakeholders who play different roles. Psychologists and social workers for an example may help to promote emotional wellness among juvenile offenders while on the other hand medical personnel may help promote physical wellness through the treatment of different diseases.

\section{Methodology}

Qualitative research design was used in this study to enable the collection of data in the natural settings and to give participants the opportunity to express their experiences with regard to wellness (Creswell 2013). This method also allowed the researcher to focus on the perspective of participants, bearing in mind the context in which wellness was taking place (Braun \& Clarke 2013). Since the focus was on the wellness of juvenile offenders, the phenomenological approach was seen as the relevant approach owing to its focus on a specific phenomenon (Rashid Shah \& AlBargi 2013). To discover meanings attached by juveniles on their behaviour and how they interpreted their situations the interpretive paradigm was used (Woods 2006). Purposive sampling was used to select participants who were learners at correctional schools and teachers who were involved in the education of juveniles there. In each school three juveniles and two teachers were selected to participate. Open ended questionnaires were used as data collection instruments to allow participants to express their experiences and opinions.

The researcher got permission from the Department of Correctional Services as well as the University of South Africa's ethics committee before embarking on the study. Participants were informed about the purpose of the study as well as the procedures to be followed including the anonymity and confidentiality of their identities. They were also informed about their rights including the right to withdraw from the study without any penalty. Consent forms were completed by participants before the study commenced.

\section{Data Analysis}

As data was qualitatively collected, qualitative approach was used to analyse this data through coding, categorising and developing themes (Henning, Van Rensburg \& Smith 2010). The researcher started by colour coding findings with similar meanings which were later put into categories according to similarities in meanings. These categories 
were then merged according to meanings to form themes. These themes formed headings of findings and were used as headings in discussing findings.

\section{Findings from the study}

\section{Promotion of physical wellness}

Juveniles were involved in a number of sporting and recreational activities that promoted their physical wellness. Both schools provided a variety of sporting activities ranging from soccer, rugby and many more. Soccer was the most popular sport based on the responses given by juveniles when asked which sports they were involved in. In school A, the responses were as follows; Participant 1 "Yes, ^play soccer" and Participant 2, "Yes, soccer". On the contrary in School B participation was not adequate as confessed by Participant 1 said, "No" and Participant 3 also said "No". In School A, there was also mention of external stakeholder involvement in the promotion of the physical wellness of juveniles as teacher Participant 1 explained, "... sometimes external companies come to provide extra programmes". The involvement by external stakeholders seemed to be limited as they were only mentioned by one participant in one school.

Medical personnel were the other stakeholders who were mentioned as being actively involved. Both juveniles and teachers confirmed the existence of medical centres and personnel in their centres. The revelation came when juveniles were asked if there were medical facilities in their centres. Participant 1 in school A said, "Yes, hospital in the centre" and Participant 3 was also in agreement when he stated, "Yes, Hospital/clinic in the centre". Teachers also concurred with what juveniles said as participant 1 puts it, "Hospital with qualified staff" and Participant 2 explained further by saying, "There are medical sisters on duty 24 hours a day as well as a medical doctor who comes on Thursdays".

\section{Inadequate career guidance}

In both schools, juveniles expressed dissatisfaction at the lack of adequate career guidance to help them make informed career choices. When asked if they had received career guidance, there were negative sentiments from Participant 1 in school A who said "I have not received any guidance at this centre", and Participant 2 who also said, "Not yet, but still studying". This indicated that career guidance was not adequately provided. In school B, Participant 3 also made a negative remark on career guidance when he stated that one of the challenges he was facing with regard to career choices was, "Lack of information on careers".

On the contrary, teachers in School A said that they were providing some form on guidance on careers as Teacher Participant 1 said, "I provide career guidance as a Life orientation educator. There is also a psychologist to assist". Participant 2 also indicated that he was aware that some form of career guidance was being offered at the school as he recalled, "LO covers career guidance, Career days at college (name given) but only 
if inmates qualify to leave the centre temporarily". In school B one teacher was not aware of any career guidance being provided to juveniles but Participant 1 declared, "Yes, two educators are qualified career counsellors. We assist learners with career guidance. We host a career day once a year where we invite external stakeholders".

The contradictions from teachers and juveniles cast suspicion on what was really taking place. It is however clear that the dissatisfaction expressed by juveniles who are supposed to be the recipients of such programmes indicate that the programme was not adequately provided.

\section{Promotion of spiritual wellness}

Religious and some spiritual groups were credited for playing a pivotal role in promoting the spiritual wellness of juveniles. The acknowledgements came from both juveniles and teachers in the study. According to teachers, religious groups were frequently interacting with juveniles and offering the much needed spiritual and emotional support. Revelations came out when teachers were asked if there were religious groups that were coming to visit juveniles. Participant 2 in school A said, "Yes, Different groups from different dominions". In school B also different religious groups were also involved as alluded by Participant 1 when he confirmed by saying, "Yes, Christian groups, Muslim groups and Rasta groups etc.". The visit by religious groups played a very significant role as juvenile Participant 3 in school A explained that, "... they teach me about good things in life". Juvenile Participant 1 also expressed satisfaction on the impact these groups had on his faith when he declared, "Yes, they help me by spreading the word of God as I believe in God ..." In school B also complementary sentiments were echoed by juveniles as Participant 1 puts it, "They encourage me to learn and behave well". Participant 2 expressed spiritual and emotional fulfilment as a result of the interaction with these groups as he optimistically said, "Yes, they encourage us, give us hope, help me feel accepted".

Besides external spiritual stakeholders, these centres had their own spiritual offices with spiritual workers who were providing spiritual and emotional support to juveniles. Teachers gave testimony to the availability of such services as in school B, Participant 2 explained when asked if internal service providers were available and utilised by saying, "Yes, there are spiritual workers that come on a daily basis to facilitate programmes.". In school A, the availability of such officials and services were also confirmed by Participant 1 when he indicated this as another way of providing spiritual support by saying, "Also from members working in the units and the spiritual care offices".

Findings therefore revealed that both internal and external stakeholders were playing a significant role in promoting the spiritual and emotional wellness of juvenile offenders. These initiatives seemed to have had a positive impact on imparting the wellness of juveniles by helping them to cope with their stay in correctional centres. 


\section{Provision of psycho-social support}

The emotional and social wellness of juvenile offenders were promoted through the involvement of different stakeholders from both within and outside correctional centres. Social workers and psychologists were identified as the most valuable service providers in this regard. Despite teachers indicating that they were referring most cases to psychologists, some juveniles were not satisfied at the services provided by these stakeholders. Participant 1 in school A was not convinced at usefulness of social workers and psychologists when asked about the psycho social support he got in correctional centres by saying, "I get only support from my family who come and visit". Participant 3 also painted a negative picture on the services provided by social workers and psychologists when he explained how he dealt with emotional stress by saying, "I talk to others/communicate with people, roommates".

Teachers on their side indicated that they had limited capacity to help juveniles and most of the cases that required emotional and psychological support were referred to social workers and psychologists. Participant 1 in school A indicated that he referred such cases to "Psychologists as well as social workers". Participant 2 also echoed the same sentiments by stating that, "Psychologists come to the centre". They further explained that it was not only psychologists and social workers who were actively involved in this regard but there were other stakeholders involved. Participant 1 elaborated by saying, "Unit managers and Case officers provide support". Participant 2 further elaborated by saying, "Social workers have programmes that involve the inmates support structures e.g. family if needed". Participant 1 in school B further stated that he was also getting involved in assisting juveniles when he said, "I counsel them".

\section{Promoting intellectual wellness}

In an endeavour to promote the intellectual wellness of juveniles, teachers were using different resources as Participant 1 in school A stated that he was using, "Technological resources where possible and visual resources". Participant 2 on the other hand mentioned the use of, "Library, internet, media, newspapers, magazines and speakers". Despite putting more effort to provide quality education, teachers were facing various challenges as noted by Participant 2 in school B who complained by saying, "We don't have many resources. That is our challenge. We use textbooks". Some resources could not be used unfortunately as Participant 1 in school B further commented that, "... books, periodicals. Unfortunately, no newspapers as we try to discourage smoking".

The library services have a role to play in promoting the intellectual wellness of juveniles. In both schools, library services were available. The utilisation of these services however seemed to be a bit limited because of different reasons. Some juveniles felt the books in their libraries were of no significant value as Participant 1 complained that, "There are not enough books in the library". Participant 2 in the same 
school confessed that he didn't utilise the service when he said, "I have never used it even once". In school B the availability of library services was acknowledged by juveniles when they were asked if there were such services as Participant 1 said, "Yes", Participant 2, "Yes" and Participant 3 also said, "Yes".

In contradiction to the views of juveniles, teachers were satisfied with the library services. This was attested by responses by teachers in school A when asked if the library was fully functional as both Participant 1 and 2 said, "Yes". In school B, participants even stressed that the use of library services was reinforced as Participant 1 explained, "Visiting the library is compulsory". Participant 2 went further to elaborate by saying, "On Fridays we have reading sessions to assist them with their reading and writing skills and also motivate them to use the library." The contradictions from juveniles and teachers may indicate that library services were available although their utilisation by juveniles seemed to have been limited.

As part of attaining intellectual wellness, individuals need to keep up to date with current affairs. Incarceration may limit easy access to information. Keeping in touch with what happens in the outside world may help offenders to easily adjust when they are released. Responses were different when juveniles were asked how they got up to date with the outside world. Some of them seemed to be confined to their spaces and had little access to what was happening outside as Participant 1 in school A remarked, "Not up to date". In school B, things seemed different as corroborated by Participant 2 with this statement, "I watch TV, listen to the radio. Weekend I am out of prison and from coaches outside". Participant 3 also indicated a similar situation when he said, "TV, news, Radio."

\section{Discussion of Findings}

\section{Promotion of physical wellness}

The availability of SRAC programmes was seen as a positive move towards the promotion of physical wellness. Physical activities and exercises in particular have been identified as good habits for promoting physical wellness (Hetler 1976). Lack of participation in these programmes was a cause for concern to the researcher as this may have a negative impact on the promotion of physical wellness. Various stakeholders who facilitated the implementation of such programmes also deserve to be commended. Having medical facilities and health personnel in correctional centres was also applauded as the health of juveniles were taken care of. The promotion of physical wellness involves offering treatment when one has been affected by diseases (Hetler 1976). In the United States of America 47\% deaths were reported in 1999 due to lack of proper medical care (Shirk 2009). This shows that lack of medical care can have severe consequences and hinder the promotion of physical wellness. A report made to the Parliament of South Africa in 2014 stated that there were skills shortages in the medical field in South African correctional centres (Parliamentary Monitoring Group 2014). For this reason, expressions by juvenile offenders that the services 
provided were not satisfactory cannot be dismissed. More health personnel should be employed in juvenile centres in order to promote the physical wellness of juveniles more effectively.

\section{Inadequate career guidance}

Career guidance and counselling help learners to choose careers that are consistent with their interests and abilities thereby leading to job satisfaction (Hetler 1976). Inadequate career guidance as expressed by juveniles on the other hand may result in juveniles choosing careers that are not consistent with their personalities and capabilities. This may result in many juveniles not pursuing careers where they can attain job satisfaction and stay longer. Job dissatisfaction may result in released offenders going back to crime. Lack of career guidance in correctional schools were also reported in Gauteng previously where it was revealed that most juveniles were not getting adequate guidance (Magano 2016). There is need for more vocational training and programmes that may lead to employment because getting employment may lead to change in behaviour by offenders (Ngabonziza \& Singh 2012). In Los Angeles, USA, even though juveniles are sent to restricted settings as a last resort, authorities ensure these settings have high staff supervision and ensure offenders attend school and get involved in some of vocational training (Los Angeles County Probation Department 2013). The system seems to work well as most offenders get employed after release.

The involvement of Non-Governmental Organisations such as Khulisa and Brothers for Life in South Africa who organise job placements for released offenders is a positive move by the Department of Correctional Services in engaging relevant stakeholders. Such initiatives should be intensified for the benefit of released offenders especially juveniles. Curriculum in correctional schools should also be aligned to the needs of the job market to enable graduates from such schools to compete positively with others in the job market. Schools should liaise effectively with potential employers and institutions that offer training in order to have relevant and useful educational programmes (Macomber et al 2010). During career expositions, as was the case with one school, the net should be cast wide to expose juveniles to a wide range of careers so that juveniles get as much information on careers as they can.

\section{Promotion of spiritual wellness}

In both schools that took part in the study, the involvement of religious based organisations as well as spiritual workers were reported to be positive. These organisations were also reportedly to be actively involved even in previous years such as in 2014 where it was reported that there were 1794 spiritual workers providing services to inmates (Parliamentary Monitoring Group 2014). The involvement by spiritual workers has been identified as pivotal in the rehabilitation of offenders and their engagement has been utilised in other countries such as Myanmar (Korff 2010). 
Spiritual intervention helps to create hope among inmates and create a sense of purpose and meanings in their lives (Palmbeach 2017). It also helps in behavioural change as attested by most juvenile participants as well as teachers. Effective promotion of spiritual wellness also helps offenders to change their attitudes and to be in a better position to understand the consequences of their actions (Hawley 2011).

\section{Psycho social support}

In South Africa, rehabilitation is viewed as a societal responsibility although the Department of Correctional Services takes a leading role (Department of Correctional Services 2005). The correctional officer should be a role model and rehabilitator as he is in a position to positively or negatively persuade offenders. In China, correctional officers are expected to act like parents to offenders (Chen 2000). Teachers are also in the forefront of rehabilitation especially in South Africa where education and training are placed as the core processes of offender rehabilitation (Department of Correctional Services 2005).

Family involvement is also crucial in offender rehabilitation (Department of Correctional Services 2005). Findings in this study revealed that although most schools were trying to involve family members of juveniles, there was in actual fact inadequate participation by the family as a unit. Prior findings also revealed that in 2012, 40\% of juveniles in correctional centres in South Africa had no family visits in three months (Muntingh \& Ballard 2012). There has been a global call for juveniles to be incarcerated closer to their families as this has proven to improve their mood and reduce chances of re offending (Walker \& Bishop 2016). On the contrary, incarcerating juveniles far from their homes leads to exposure to anti-social peers and in Scotland it was reported to be responsible for about $14.5 \%$ suicide attempts among juveniles in detention (Little 2006). The Family Functional Therapy is a typical example of a system that make use of family involvement in rehabilitation. In this approach, the family is equipped with tools needed for problem solving and after care parenting (Greenwood 2006). However, the global transformations in family structure has resulted in negative family involvement. In particular, dysfunctional and broken families pose a challenge in establishing family contacts (Korff 2010).

Partnerships with the community is also very important and therefore correctional centres should get support from communities where juveniles come from and information should be exchanged between the two institutions (Centre for The Study of Violence and Reconciliation 2009). In this study, community involvement seemed to be lacking. Members of the community should be knowledgeable about the rehabilitation process and be willing to voluntarily participate in such programmes. Prior research findings in South Africa revealed that community partnership in offender rehabilitation was lacking and recommendations were made that this should be intensified (Parliamentary Monitoring Group 2014). 
During the study, there were mixed feelings and reactions on the role played by social workers and psychologists. These professionals play a vital role especially in promoting the emotional and social wellness of juveniles. Social workers offer counselling and therapeutic programmes while psychologists cover the juveniles' psychological aspects. Social workers also help in bringing families of juveniles in the rehabilitation intervention programmes. Whereas teachers indicated that they referred most of the matters to social workers and psychologists, most juveniles seemed not satisfied with the services provided by these stakeholders. There have been even reports of shortages of social workers and psychologists in correctional centres as in South Africa. In 2014 there were only 68 psychologists serving 150000 inmates which equates to one psychologist serving 2200 inmates (Parliamentary Monitoring Group 2014). Other countries such as Bangladesh have also experienced a shortage of psychologists as well, thereby affecting the promotion of the wellness of juveniles (Lotse 2006).

\section{Challenges in promoting intellectual wellness}

Lack of resources and personnel were identified as barriers to the provision of quality education that promotes intellectual wellness among juvenile offenders. Shortage of staff does not only deprive juveniles of the opportunity to attain intellectual wellness but has other implications such as vulnerability to abuse due to lack of supervision (Kempsi 2010). The amount of time spent in class is also very crucial. In South Africa a research was done which showed that most learners spent little time in class in Correctional schools (Muntingh \& Ballard 2012). Teachers play a significant role in promoting the wellness of juvenile offenders during rehabilitation. Even though their basic function is to offer education and vocational programmes, teachers deal with juveniles on a daily basis and are expected to offer some form of counselling to the learners under their care. Teachers therefore need specialised training to deal with juvenile offenders. As important stakeholders, teachers should also provide relevant education that can change the behaviour of offenders. In this generation, skills training may help to change the behaviour of offenders as practical training has been found to lead to more likelihood of getting employment and reducing recidivism significantly in the USA (Young, Greer \& Church 2017). Institutions of higher learning such as universities and TVET colleges should also be involved in equipping teachers with relevant skills that can help them teach more effectively and efficiently.

Resources are necessary for teaching and learning to be effective so that intellectual wellness can be promoted. These resources include books, stationery and even proper classrooms. Most juveniles expressed dissatisfaction with the quality of books in the libraries. Similar findings were reported by Magano (2016), when she stated that in one Gauteng correctional centre, the library was there but most books in that library were irrelevant. Partnership or collaboration with other stakeholders such as book publishers can go a long way in solving the problem of shortage of reading materials. Some of the stakeholders can be asked to donate relevant updated books. 
Keeping up to date with current affairs and seeking new information helps to promote intellectual wellness (Viterbo University 2006). When juveniles get up to date and current affairs information, they may attain intellectual wellness.

\section{Conclusion}

It is evident that the attainment of wellness brings a holistic approach in rehabilitation. The promotion of wellness is however a complex process bearing in mind the different dimensions that one needs to achieve in order to attain total wellness. For this reason, rehabilitation of juvenile offenders cannot be left solely in the hands of the Department of Correctional Services. Different stakeholders need to work hand in hand to ensure offenders attain these different wellness dimensions. These wellness dimensions as articulated by Hetler (1976), are social, spiritual, career, physical, emotional and intellectual. The involvement of stakeholders is necessary as each one of them can play a role in promoting a particular dimension of wellness. As much as the Department of Correctional Services has policies that outlines collaboration among stakeholders, the implementation of such policies seemed to be lacking, according to some responses given by participants. Juveniles were not satisfied by the services provided by social workers, psychologists and even teachers in some cases.

With the Department of Correctional Services shifting rehabilitation to focus more on education and training, teachers find themselves at the forefront of offender rehabilitation. For this reason, teachers should be well equipped in order to effectively promote the wellness of juvenile offenders. This can be done by providing career guidance, teaching social skills and many more. Other stakeholders also need to be actively involved to promote wellness dimensions. The study was carried out from a wellness theoretical perspective and therefore the attainment of different dimensions is seen as a prerequisite to the realisation of full wellness. From the ubuntu perspective, collective responsibility should be adopted to ensure the success of the rehabilitation programme. by bringing different stakeholders. In adopting the philosophy of ubuntu, community members work for the common good for all which include ensuring a successful rehabilitation programme.

\section{Recommendations}

Based on the findings of this study, it is recommended that different stakeholders should work in collaboration with each other in order to promote different wellness dimensions. Each stakeholder has a significant role to play in rehabilitation. There should be enough and adequately trained teachers in correctional schools to ensure effective teaching and learning. Social workers and psychologists should be proactive and not only reactive in order to avoid offenders getting into difficult situations before helping. Effective collaboration should also be in place with institutions of higher learning such as TVET colleges and universities so that they can provide skills training to both teachers and learners. Communities need to know what is happening in 
juvenile offender rehabilitation so that they can appreciate and welcome released offenders knowing that they have undergone a reformatory process through rehabilitation and correction. Having knowledge and appreciation of the rehabilitation programmes can also help destroy the stigma associated with exoffenders as being the same despite undergoing the rehabilitation process. The Chinese approach whereby public officials visit juvenile offenders during their incarceration can also help boost the moral and selfesteem of juveniles (Chen 2000). More staff members should also be employed to manage gangs. Gangs are a big threat in the promotion of wellness since they usually promote antisocial skills among offenders.

\section{References}

[1] Braun, V \& Clarke V. 2013. Successful qualitative research: A practical guide for beginners. London: Sage.

[2] Broodryk, J. 2006. Ubuntu African coping skills, theory and practice. Pretoria: Ubuntu School of Philosophy.

[3] Centre for the Study of Violence and Reconciliation. 2009. Community involvement in prisons. Available: https://www.csvr.org? [Accessed: 12 February 2017]

[4] Chen, X. 2000. Educating and correcting juvenile delinquents: The Chinese approach. Journal of Correctional Education, 51(4), 334-346.

[5] Creswell, J.W. 2013. Qualitative inquiry and research design. Choosing among five approaches. $3^{\text {rd }}$ ed. Los Angeles: Sage.

[6] Department of Correctional Services. 2005. White paper on corrections in South Africa. Pretoria: Government Printers.

[7] Dubin, J. 2012. Metamorphosis. How Missouri rehabilitates juvenile offenders. American Educator/Summer 2012.

[8] Greenwood, P.W. 2006. Changing Lives. Delinquency prevention as crime control Policy. Chicago: The University of Chicago.

[9] Henning, E., Van Rensburg, W. \& Smith, B. 2010. Finding your way to qualitative research. Pretoria: Van Schaik.

[10] Hettler, B. 1976. Six dimensions of wellness. Stevens Point: National Wellness Institute.

[11] James, C., Asscher, J.J., Jan, G., Stams, M. \& Van Der Laanm, P.H. 2016. The effectiveness of aftercare for juvenile and young adult offenders. International Journal of Offender Therapy and Comparative Criminology, 60(10), 1159-1184.

[12] Kempski, M. 2010. Juvenile detention centre abuse. Available:

[13] http://www.scribd.com/doc/384395/Juvenile-Detention-Centre-Abuse [Accessed 24 July 2014].

[14] Korff, B.P. 2010. Treatment of juvenile offenders and their reintegration into society. Pretoria: SAPS, Division: Training: Education Training and Development, Research and Curriculum Development. 
[15] Little, M. 2006. A social development model of incarceration of juvenile offenders' social network support, exposure to anti-social peers, aggressive offending and psychological adjustment. Doctoral dissertation. Philadelphia: Temple University.

[16] Lorenz, P. 2002. The education centre, Fort Mitchel prison, Spike Island. Journal of Correctional Education, 53(2), 65-69.Los Angeles County Probation Department. 2013. Los Angeles County probation department's 2012 annual report.

Available: http://file.lacounty,gov/probation/cms1_197736.pdf [Accessed 17 November 2016].

[17] Lotse, C. 2006. Juvenile justice in South Asia: Improving Protection for Children in conflict with the Law. Available:

[18] http://www.unicef.org/rosa/JuvenileinSouthAsia,pdf. [Accessed: 14 March 2015].

[19] Macomber, D., Skiba, T., Blackmon, J., Hart, L., Mambrino, E., Richie, T. \& Grigorenko, E.L. 2010. Education in juvenile detention facilities in the state of Connecticut: A glance at the system. The Journal of Correctional Education, 61(3), 223-261.

[20] Magano, M.D. 2016. The academic wellness and educational success of juvenile offender in a Gauteng correctional school. Educational Research for Social Change, 5(1), 148-152.

[21] Mangena, E. 2016. African ethics through ubuntu: a postmodern exposition. Africology. The Journal of Pan African Studies, 9(2), 66-80.

[22] Maphalala, M.C. 2017. Embracing ubuntu in managing effective classrooms, Gender and Behaviour, 15(4), 10237-10249.

[23] McAree, T. 2011. Prisoner rehabilitation in South Africa: A case study of Phoenix Zululand's work in Eshowe Correctional facilities. Available: http://phoenix- zululand.org.za/wp-content/uploads/2012/01/tommyISP-_2_.pdf

[24] Metz, T. \& Gaie, J.B.R. 2010. The African ethic of ubuntu/botho: Implications for research on morality. Journal of Moral Education, 39(3), 273-290.

[25] Muntingh, L. \& Ballard, C. 2012. Report on children in prison in South Africa. Cape Town. Community Law Centre.

[26] National Institute for Crime Prevention and the Reintegration of offenders (NICRO). 2009. National Annual Report. Johannesburg: NICRO.

[27] National Institute for Crime Prevention and the Reintegration of offenders (NICRO). 2014. The State of South African prisons. 1 $1^{\text {st }}$ ed. Johannesburg: NICRO Public Education Series.

[28] Ngabonziza, O. \& Singh, S. 2012. Offender reintegration programme and its role in reducing recidivism, Exploring perceptions of the effectiveness of tough enough programme. Acta Criminological: Southern African Journal of Criminology: CRIMSA 2011 Conference (Special Edition, 2), 87-102.

[29] Palmbeach. 2017. Wellness dimensions. Available: 
[30] http://www.palmbeach.klz.fl.us/wellness/dimensions [Accessed 21 May 2017].

[31] Parliamentary Monitoring Group. 2014. Rehabilitation and reintegration programme challenges, Correctional Services briefing, 17 September 2014. Cape Town: Parliament of South Africa.

[32] Rashid Shar, S. \& Al-Bargi, A. 2013. Research paradigms: Researchers' worldviews, theoretical frameworks and study designs. Arab World English Journal, 4 (4): 252264.

[33] ReAducate. 2012. Prisoner Rehabilitation. Available: http://readucate.org/pages/prison_programme.htm [Accessed: 10 April 2016].

[34]Shirk, M. 2009. Health care in juvenile detention centres. Available: http://www.reportingonhealth.org/fellowships/projects/health-careJuveniles- detentioncentres. [Accessed: 6 May 2015].

[35] Shrum, H. 2004. No longer theory. Correctional practices that work. The Journal of Correctional Education, 55(3), 225-235.

[36] Tutu, D. 1999. No future without forgiveness. London: Rider, Random House.

[37] Walker, S.C \& Bishop, A.S. 2016. Length of stay therapeutic change and recidivism for incarcerated juvenile offenders. Journal of Offender Rehabilitation, 55(6), 355376.

[38] Wamsley, R. 2012. World female imprisonment list. $2^{\text {nd }}$ ed. London: International Centre for Prison Study.

[39] Woods, P. 2006. Qualitative research. Plymouth. University of Plymouth.

[40]Young, S., Greer, B. \& Church, R. 2017. Juvenile delinquency, welfare, justice and therapeutic interventions: A global perspective. BJPsych Bulletin, 41(1), 21-29. 